\title{
Nanoencapsulation II. Biomedical applications and current status of peptide and protein nanoparticulate delivery systems
}

\author{
Catarina Pinto Reis, MS, ${ }^{\text {a }}$ Ronald J. Neufeld, $\mathrm{PhD},{ }^{\text {b,* }}$ \\ António J. Ribeiro, $\mathrm{PhD},{ }^{\mathrm{c}}$ Francisco Veiga, $\mathrm{PhD}^{\mathrm{a}}$ \\ ${ }^{a}$ Laboratorio Tecnologia Farmacêutica, Faculdade de Farmácia, Universidade de Coimbra, Coimbra, Portugal \\ ${ }^{\mathrm{b}}$ Department of Chemical Engineering, Queen's University, Kingston, Ontario, Canada \\ ${ }^{\mathrm{c}}$ Depart. Tecnologia Farmacêutica, I. S. C. S. N.- C. E. S. P. U., Gandra, Paredes, Portugal \\ Received 10 April 2006; accepted 12 April 2006
}

Abstract

The concept of polymeric nanoparticles for the design of new drug delivery systems emerged a few years ago, and recent rapid advances in nanotechnology have offered a wealth of new opportunities for diagnosis and therapy of various diseases. Recent progress has made possible the engineering of nanoparticles to allow the site-specific delivery of drugs and to improve the pharmacokinetic profile of numerous compounds with biomedical applications such as peptide and protein drugs. Biologically active peptides and their analogues are becoming an increasingly important class of drugs. Their use for human and animal treatment is problematic, however, because some of these drugs are generally ineffective when taken orally and thus have been administered chiefly by the parenteral route. This review covers some of the historical and recent advances of nanotechnology and concludes that polymeric nanoparticles show great promise as a tool for the development of peptide drug delivery systems.

(C) 2006 Elsevier Inc. All rights reserved.

Key words:

Biomedical applications; Nanoparticles; Peptides; Proteins

Peptide drugs are attracting increasing interest with better understanding of their role in physiopathology, as well as progress in biotechnology and biochemical synthesis. However, the use of peptides and proteins in medicine has been limited by low bioavailability, which results from their poor stability to proteolytic and hydrolytic degradation, low permeability across barriers, and short biologic half-life in the circulatory system [1]. Most therapeutic peptides are still being administered by the parenteral route because of insufficient absorption from the gastrointestinal tract (GIT).

Because of their versatility for formulation, sustainedrelease properties, subcellular size, and biocompatibility with tissues and cells, nanoparticles seem to be a promising solution for peptide and protein administration. Much research has been devoted to their use in the treatment of

\footnotetext{
No financial conflict of interest was reported by the authors of this paper.

* Corresponding author. Chemical Engineering Department, Dupuis Hall, Queen's University, Kingston, Ontario, Canada, K7L3N6.

E-mail address: ron.neufeld@chee.queensu.ca (R.J. Neufeld).
}

or vaccination against several diseases, because they offer several advantages over conventional dosage routes. The literature has emphasized the importance of size and revealed the advantages of nanoparticles over microparticles [2]. It has been observed that a greater number of nanoparticles crosses the epithelium than do microparticles. Nanoparticles have received more attention than have liposomes because of their therapeutic potential and greater stability in biologic fluids as well as during storage [3]. Their small particle size makes colloidal preparations well suited for parenteral administration and also possibly useful as sustained-release injections for delivery to a specific organ or target site. Targeting the drug to the desired site of action would not only improve the therapeutic efficiency but also permit a reduction in the amount of drug that must be administered to achieve a therapeutic response, thus minimizing unwanted toxic effects. To target the drug to a specific cell, recent advances in nanotechnology involve the addition of ligands to the nanoparticle surface such as through adsorption of monoclonal antibodies or other compounds such as transferrin, lectin, or avidin [4]. 
This review addresses some biomedical applications of nanotechnology and the current status of peptide delivery systems. It also describes a variety of barriers to the absorption of orally administered peptides and predicts new strategies to achieve the main objective - to improve the bioavailability of peptide and protein drugs administered by several routes, especially the oral.

\section{General absorption considerations}

In comparison with other possible routes of administration, oral peptide drug delivery has many advantages. Not only is it noninvasive and relatively free from complications arising from the need for sterile techniques that usually occurs with parenteral formulations, but it is also convenient and is easily dosed with low preparation costs, all of which should encourage patient compliance.

Considerations associated with developing effective oral formulations (see Figure 1) for peptides are generally attributed to susceptibility to degradation by luminal secreted, luminal membrane-bound, and cytosolic enzymes. Proteolysis generally starts in the stomach by a family of aspartic proteases called pepsins, which are mostly active at $\mathrm{pH} 2$ to 3 and become inactive at a $\mathrm{pH}$ greater than 5. Pepsin is normally responsible for $10 \%$ to $20 \%$ of total protein degradation. Upon reaching the duodenum, mixtures of peptides resulting from partial protein digestion in the stomach are acted upon by pancreatic proteases, consisting of the serine endopeptidase trypsin, $\alpha$-chymotrypsin, elastase, and exopeptidases carboxypeptidases A and B [5].

As shown in Figure 2, peptidases associated with the intestinal mucosa are mainly located in three subcellular fractions of the enterocytes: the surface of the brush border membrane, the intraluminal, and the intracellular fractions (cytoplasm and lysosomes) [6].

Proteases in the brush border and cytosol of the enterocyte are potentially the most important barrier to the absorption of small, biologically active peptides across the intestinal mucosa [5]. In addition to the membrane-bound proteases, trypsin, chymotrypsin, and other pancreatic proteases may be adsorbed from the luminal fluid into the brush border of the enterocyte, assisting in proteolysis of oligopeptides and proteins [5]. Those peptides whose N-terminal amino acid residues possess a lipophilic side chain are preferred substrates for the brush border enzymes. Brush border proteases as a group tend to prefer tri- and tetrapeptides, although they also readily hydrolyze peptides in the range of 2 to 10 amino acids. Specifically, about $60 \%$ of the cellular proteolytic activity against tripeptides and $90 \%$ of the activity against tetrapeptides can be found in the brush border.

In contrast, the general cytosolic proteases have a preference to smaller di- and tripeptides with slight activity against tetrapeptides. The soluble enzymes of the cytoplasm consist mainly of dipeptidases, an aminotripeptidase, and proline dipeptidase and prolidase, which serve to complete the intracellular hydrolysis of di- and tripeptides that are actively transported across the brush border membrane by a proton-dependent carrier mechanism [7].

Intracellular peptide and protein degradation may also take place after endocytosis and uptake into the lysosomes. Proteolytic degradation in the lysosomes is essentially catalyzed by cathepsins and may involve exopeptidase as well as endopeptidase activities [8].

Unlike other drug compounds, peptides and proteins are susceptible to degradation at many anatomic locations. As well, a given peptide or protein usually is susceptible to degradation at more than one linkage within the molecule [5].

Another concern is the metabolic activity of microflora in the lower small and large intestine, especially with respect to colonic peptide delivery strategies. Colonic microflora are composed of more than 500 species consisting of $10^{11}$ to $10^{12}$ bacteria per gram of gut content, and are capable of several metabolic reactions, such as deglucuronidation, decarboxylation, reduction of double bonds, ester and amide hydrolysis, and dehydroxylation [9].

The types of enzymes encountered, the many locations for these enzymes in the body, and the multiplicity of potential sites of degradation on the molecule suggest that there will be an upper limit to the percentage of an applied dose of peptide or protein that reaches the target site.

Another difficulty with developing effective oral formulations for peptide and protein drugs involves the poor intrinsic permeability of peptides and proteins across biologic membranes, which usually prevents passive transport as a result of large molecular size, charge, and protein hydrophilicity [10].

The tendency of peptides and proteins to be larger than many biologically active molecules, ranging from less than 0.6 to greater than $10 \mathrm{kDa}$ in a nonaggregated state, limits their uptake through aqueous pores in the gut wall. In the human intestine pore permeability for small molecules, ions, and water is highest in the jejunum, intermediate in the ileum, and lowest in the colon [5]. The pore diameter of the mucosa (with a range from 8 to $16 \AA$ ) can be considered an important consideration in the transport of peptide molecules [11]. Compounds with molecular sizes greater than these dimensions will thus be excluded. The pore diameter of the mucosa has been found to be modified by absorption enhancers such as calcium chelators, fatty acids, or surfactants [12]. An additional consideration for transport is the charge carried by the molecule. Because negatively charged groups predominate around the intestinal pores, neutral or cationic compounds should pass more easily through these paracellular aqueous pores than do anionic compounds. Amino acids and proteins also have exceptional acid-base properties. The 20 standard $\alpha$-amino acids have at least two acid-base groups. The $\mathrm{p} K_{\mathrm{a}}$ values of the carboxylic groups lie in a small range around 2.2, so that above $\mathrm{pH} 3.5$ these groups are entirely in their carboxylate form. All $\alpha$-amino acids have $\mathrm{p} K_{\mathrm{a}}$ values near 9.4 and are almost completely in the ammonium ion form below $\mathrm{pH}$ 8.0. Of the 20 standard amino acids, 5 have charged side chains. The 


\section{PEPTIDES AND PROTEINS}

\section{Step 1 \\ Physicochemical and therapeutic properties:}

1-Characteristics of peptides and proteins including: $\mathrm{pKa}$, molecular weight, molecular size, lipophilicity and solubility,

2- Efficacy of peptides and proteins including: stability, stereochemical structure, electrical charge, affinity to receptor;

3- Identification of the optimal absorption site for a given peptide or protein.

\section{Pharmaceutical factors}

1- Appropriate drug targeting: mucoadhesion and mechanical fixation;

2- Enzyme inactivation; enzyme inhibitors and chelators agents;

3- Absorption enhancement: bile salts, surfactants,

polymers such as trimetyl- chitosan.
Step 2

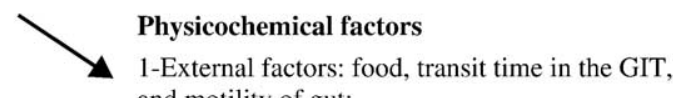
and motility of gut;

2-Internal factors: mucus layer of lumen, bloodflow rate, $\mathrm{pH}$ of intestine and surface membrane of intestine;

3-Mechanical factors: luminal enzymatic degradation, transcellular or paracellular absorption and intercellular metabolism.

Developing appropriate drug delivery system such microparticulate system, liposomes, nanoparticles, ...

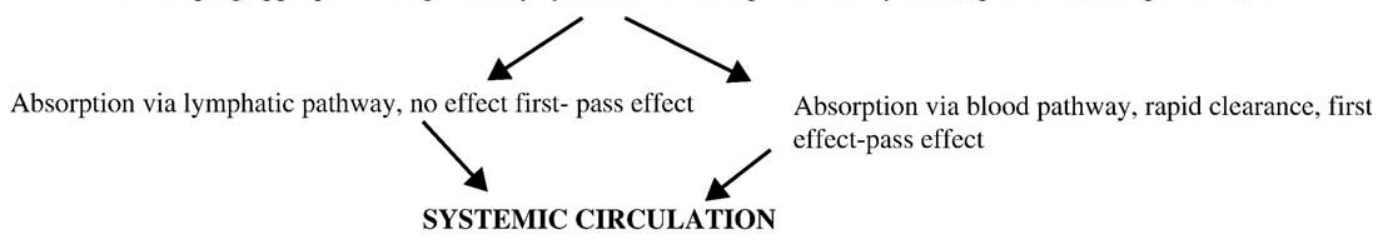

Fig 1. Schematic flowchart illustrating the issues to be addressed when developing oral peptide and protein drug delivery systems. Adapted from Dorkoosh et al. [125].

basic amino acids lysine, arginine, and histidine are all positively charged at physiologic $\mathrm{pH}$, whereas aspartic and glutamic acids are negatively charged above $\mathrm{pH} 3$. In the physiologic $\mathrm{pH}$ range both the carboxylic acid and amino groups of peptides and amino acids are entirely ionized, resulting in a zwitterionic molecule. Therefore, peptides and proteins will tend to be more hydrophilic than many other biologically active molecules. This characteristic would most likely preclude the absorption of peptides and proteins by transcellular diffusion unless the charges were neutralized through ion pairing [5]. With few exceptions, peptides tend to be relatively insoluble in lipids and thus are confronted by a thermodynamic barrier even when the concentration gradient across the absorptive membrane is favorable. Clearly, neither size and charge nor subsequent hydrophilic character favors the transit of larger peptides and proteins across the mucosal membrane [5].

Another difficulty with particulate oral formulations of peptide and protein drugs is their high water solubility. Most processes for nanoencapsulation are based on the affinity of the compound for the lipophilic phase of an emulsion or for the polymer. As a result, drug loading is usually less then $10 \%$, especially with the solvent evaporation process [13].

Chemical instability of peptides and proteins is another barrier to particulate formulation of peptides, including their tendency to aggregate and/or adsorb to a variety of physical and biologic surfaces [10]. Peptides and proteins often possess physical properties that present significant formu- lation problems not encountered with many small organic drug molecules. Because of the complex nature of peptides, self-aggregation is always a concern in the formulation. Other factors such as sensitivity of the peptide and proteins to light, heat, moisture, $\mathrm{pH}$, intermolecular interactions following co-precipitation or gelling, adsorption and interaction with excipients are parameters which should be investigated in order to succeed in producing a stable association of peptides with nanoparticulate systems [13].

Many peptides and proteins are susceptible to presystemic metabolism with rapid postabsorptive clearance not limited to hepatic extraction. They may remain susceptible to degradation at other sites within the body (for example, kidneys and blood) and while crossing the vascular endothelia to the site of action [5]. Significant intestinal epithelial cell enzymatic activity is the first postabsorptive barrier to achieving therapeutic systemic levels. Unlike many traditional drug candidates, peptides are also highly susceptible to enzymatic degradation in the circulating blood [14]. Opsonization by blood cells must also be considered, but this review's focus is on nanoencapsulation and its applications to peptidic drugs, so we will not address further the subject of postabsorptive metabolism and peptide clearance.

A significant obstacle to orally administered peptidic nanoparticles is the intestinal diffusion barrier, because of particular physical and chemical characteristics. To be absorbed a specific peptide must cross the barrier, which comprises an unstirred water layer, mucus layer, apical and 


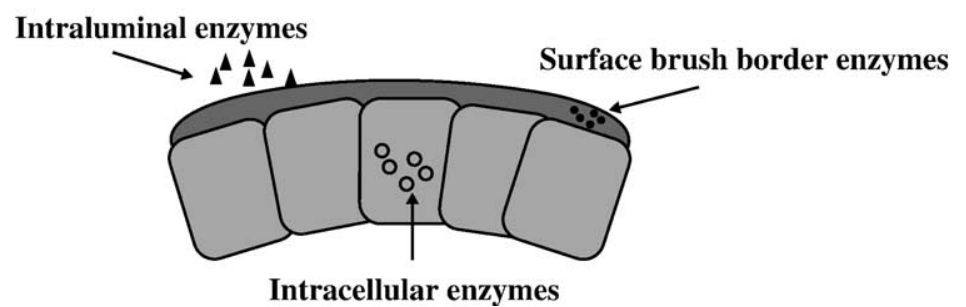

Fig 2. Sites of enzymatic degradation of peptides and proteins in the small intestine.

basal cell membranes and cell contents, tight junctions, basement membrane, and the walls of lymph and blood capillaries. Structure, composition, thickness, surface area, and $\mathrm{pH}$ of this barrier are important considerations in drug delivery systems.

Several mechanisms inhibit peptide access to the site of action. By itself, the peptide cannot overcome the previous barriers. Thus major efforts have been directed toward reaching the target of effective and safe formulations for peptide and protein drug carriers. Several strategies that have been developed involve liposomes [15], emulsions $[16,17]$, microcapsules $[13,18,19]$, and nanoparticles $[20,21]$. Some authors have suggested that nanoparticles may improve the bioavailability of peptide or protein administered orally. Nanoparticles can actually protect these labile drugs from the previous barriers and enhance their absorption by optimizing their interaction with the absorption site in the gut wall or by directly transporting them through the intestinal mucosa to systemic circulation [22]. Various mechanisms have been proposed to explain the translocation of particulate material across the intestine: (1) uptake via Peyer's patches (PP) or isolated lymphoid follicles [23-26], (2) intracellular uptake [26,27], and (3) intercellular/paracellular passage [26,28]. Among these three mechanisms, translocation via uptake in PP seems to be a major pathway for rapid and substantial passage after oral administration of nanoparticles [29]. Although possible in some situations, passage of particles between the absorptive cells is less likely if the barrier of tight junctions has not been disrupted. Although there are numerous reports showing evidence of absorption of particulate systems by the GIT, the fate of nanoparticles after oral absorption remains a controversial issue [30-32]. However, even though there is a need for better quantification of particle absorption as well as a more thorough understanding of the variables affecting particle uptake, it must be concluded that translocation of nanosized particles is possible. The question remains whether the extent of particle translocation is compatible with a strategy of drug administration with therapeutic objectives [20].

\section{Definition of nanoparticles}

Nanoparticles are solid sub-micronic drug carriers of natural, semisynthetic, or synthetic polymeric nature in the nanometer size range $[20,33]$. Nanoparticles may or may not be biodegradable and can be defined as solid colloidal particles containing an active substance that are produced by mechanical or chemical means. Nanoparticles are a collective name for nanospheres and nanocapsules as illustrated in Figure 3. Nanospheres have a matrix-type structure. Drugs or tracers may be absorbed at their surface, or entrapped or dissolved within the particle. Nanocapsules are vesicular systems in which the drug is confined to a cavity or inner liquid core surrounded by a polymeric membrane [20]. In this case the active substances are usually dissolved in the inner core but may also be adsorbed at their surface [34].

\section{Biomedical applications}

\section{Oral administration}

Oral delivery, in which the therapeutic agent is absorbed from the GIT, is the most desirable approach, but success with peptides and proteins is limited by barriers to peptide and protein absorption from the GIT. Nanoparticles can be used to protect a labile drug from degradation in the GIT, protect the GIT from drug toxicity, and deliver antigens to the PP for oral immunization [35]. Briefly, nanoparticles have been used as oral drug carriers for several reasons:

1. Improvement of the bioavailability of drugs with poor absorption characteristics [36,37]

2. Prolongation of the residence time of drugs in the intestine

3 . High dispersion at the molecular level and consequently increase of absorption

4. Delivery of vaccine antigens to gut-associated lymphoid tissue $[23,24,38,39]$

5. Control of the release of the drugs $[40,41]$

6. Targeting of therapeutic agents to a particular organ and thus reducing toxicity [42]

7. Reduction of the GI mucosal irritation caused by drugs $[43,44]$

8. Assurance of the stability of drugs in the GIT $[45,46]$

The next section describes examples of peptide and protein drugs that are being investigated for oral administration.

\section{Insulin}

Insulin is generally administered by injection in the treatment of diabetes mellitus. However, insulin injected subcutaneously seeps into the general circulation, thereby exposing all tissues to an equal concentration and providing the liver with only a fraction of the injected dose. Muscles and 

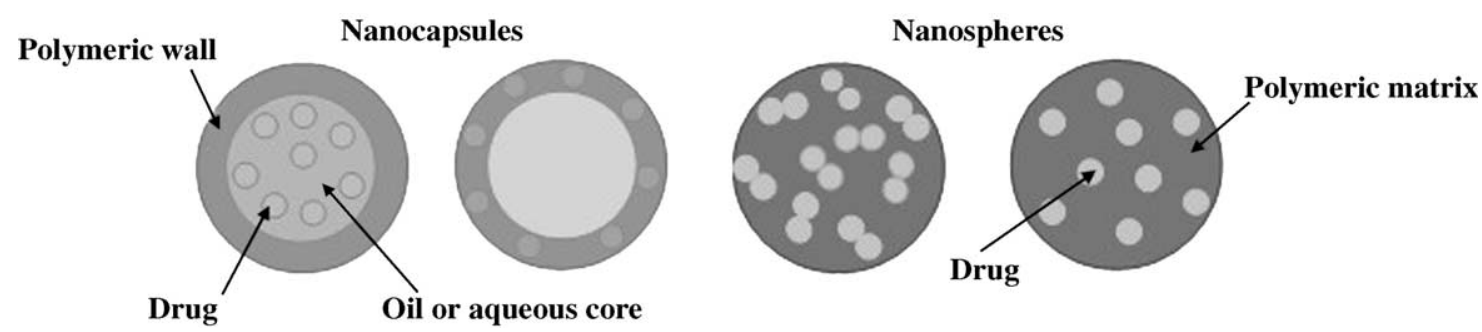

Fig 3. Schematic representation of polymeric nanoparticles.

adipocytes can thus respond to the injected dose without hepatic monitoring of the insulin supply. The excessive exposure of the vasculature and other smooth muscles to injected insulin may trigger deleterious overstimulation of growth, cell division, and other metabolic responses that form the continuum of diabetic complications [47]. Thus injections may cause local side effects and allergic reactions that may lead to physical and mental pain. Oral administration has been attempted for insulin delivery and multiple strategies have been developed, such as coating insulin pellets with a biodegradable azopolymer [48] that is degraded by bacteria in the colon [25], emulsifying the insulin [49], or using drug carriers such as liposomes [50] or nanoparticles [51-55].

First, polymer-free insulin nanoparticles were prepared [54] forming $200 \mathrm{~nm}$ nanoparticles from a neutral insulin solution by desolvation of the insulin followed by crosslinking with glutaraldehyde [19]. Later, insulin was encapsulated into poly(isobutylcyanoacrylate) (PIBCA) nanoparticles by interfacial polymerization $[51,56]$. Encapsulation would protect the insulin against proteolytic enzymes and promote absorption by the intestinal mucosa [57]. There is evidence that nanoparticles may be able to pass from the gut lumen to the blood compartment by means of a paracellular pathway [28,58]. These insulin-containing nanocapsules induced a significant hypoglycemic effect for several days in fasting and fed diabetic rats but were ineffective in normal rats [51]. This long duration of hypoglycemic effect was attributed to a retarded passage [51] and progressive arrival of intact nanoparticles containing the insulin through the gut mucosa or postabsorptive steps [59]. Thus a slow process of redistribution from that organ and/or a slow release of insulin from nanocapsules could occur. Later studies showed that insulin did not react with the alkylcyanoacrylate monomer during nanocapsule formation and was located within the oily core rather than adsorbed on the surface $[29,52]$, and the prolonged action could be due to the retention of a portion of the colloidal system in the GIT.

Many polymers and methods have been investigated to increase the bioavailability of oral insulin including insulinPIBCA nanospheres prepared by emulsion polymerization [60,61]. Particles had a mean size of $150 \mathrm{~nm}$. A lack of protection against proteolytic enzymes was observed when the spheres were suspended in water. However, when dispersed in Mygliol (Dyna-France, France), the oily medium conferred good protection against proteolysis.
These observations indicate that, with the emulsion polymerization technique, hydrophilic peptides tend to diffuse out to the surface of the formed particles, thus limiting their protection.

As well, insulin microspheres coated with Eudragit L100 (Higuchi Co., Ltd., Tokyo, Japan) and containing a protease inhibitor have been studied and found to provide effective protection against degradation by pepsin [62]. Microspheres containing insulin with aprotinin administered orally to diabetic rats induced a significant and continuous hypoglycemic effect [18]. The same insulin microspheres without protease inhibitor produced no marked hypoglycemic response. Thus a strategy that utilizes a promoter of absorption or protease inhibitor in association with microparticles or nanoparticles may be useful for enhancing the efficacy of oral insulin formulations. Of course, repeated administration of such a cocktail may cause damage to the gastric mucosa and disturb the natural process of digesting dietary proteins [20].

Insulin was also encapsulated in a blend of poly(fumaric anhydride) (poly(FA) and poly(lactide-co-glycolide) (PLGA) at a 50:50 ratio (poly(FA:PLGA)) using the inversion phase method, leading to a mean particle size of $96.7 \mathrm{~nm}$ [63]. Animals fed the poly(FA:PLGA)-encapsulated insulin preparation showed a better ability to regulate glucose load than did the controls, suggesting that the insulin crossed the intestinal barrier and was released from the microspheres in a biologically active form [63].

Insulin has also recently been encapsulated in watercontaining nanocapsules [55], which when dispersed in a biocompatible microemulsion, could facilitate intestinal absorption, as demonstrated by a reduced blood glucose level observed in diabetic rats [64].

Other techniques have been developed to encapsulate insulin such as gas antisolvent [65], spray-drying [66], ionotropic gelation [67], and dispersion polymerization technique [68]. The new advances in nanotechnology applied to insulin are focused on searching for safer, simpler, and scalable methods by using naturally occurring polymers such as alginate.

\section{Octreotide}

Polyalkylcyanoacrylate (PACA) nanocapsules have been used as biodegradable polymeric drug carriers for subcutaneous and oral delivery of octreotide, a long-acting somatostatin analogue that has the ability to reduce secretion of 
insulin or of prolactin in response to estrogens. Somatostatin is a naturally occurring tetrapeptide expressed by the hypothalamus and GIT complex, exerting pluripotent biologic actions. In addition to its central growth hormone releaseinhibiting effect, it depresses many endocrine and exocrine secretions (insulin, glucagon, pancreatic polypeptide, pancreatic enzyme, and bicarbonate), responses to cholecystokinin and secretin, and reduces GI motility and blood flow. However, its short half-life necessitates administration by intravenous infusion.

Octreotide, a synthetic octapeptide, has a long half-life and many advantages over somatostatin. Administered orally to estrogen-treated rats, octreotide-loaded nanocapsules improved (higher than $72 \%$ ) the reduction of prolactin secretion, increased plasma octreotide level, and also improved and prolonged the therapeutic effect of a somatostatin analogue given by the oral route [60].

\section{Nanoparticles loaded with luteinizing hormone releasing hormone (LHRH)}

It is known that drug-polymer conjugates, such as labile peptides coupled to hydroxypropylmethacrylamide or polyethylene glycol, are effective formulations for enhancing drug stability and improving targeting possibilities [19]. However, incorporating peptide into particles has proven to be a more efficient way to protect the peptides against proteolytic breakdown [19].

Both of these strategies were combined to synthesize a novel drug-polymer conjugate that forms its own nanoparticulate delivery system, which was named the copolymerized peptide particle system $[69,70]$. Copolymeric nanospheres were stable in vitro when incubated for 3 hours in gut luminal contents, mucosal scrapings, fetal calf serum, and rat serum [19]. LHRH-loaded copolymerized peptide particle systems (mean size of $100 \mathrm{~nm}$ ) were administered orally, and encapsulant was measured by antibody radioimmunoassay (RIA), showing a half-life of LHRH in blood of 2 to 8 minutes. The copolymerized peptide particle system allowed peptide detection for a prolonged period of 12 hours, whereas with the free peptide or with a LHRH-vinylacetate derivative in buffer, no detectable absorption of LHRH was observed. A maximum plasma uptake, amounting to $1.6 \%$ of the administered dose, was detected 3 hours after single dosing with the copolymerized peptide particle system. Significant levels of LHRH were detected for as long as 12 hours. In multiple daily oral dosing this amount increased in blood to $1.6 \mu \mathrm{g}$ after the second day and after 5 days. Although the fraction of the absorbed doses remained low, these results were promising considering that the RIA may have underestimated the extent of oral uptake of LHRH, because of incomplete extraction of LHRH and also the shielding effects of intact particles [19].

\section{Calcitonin}

Calcitonin is a peptide secreted by the parathyroid gland of the human body. Calcitonin has a hypocalcemic action due to inhibition of bone resorption. It improves the condition of bones by intensifying the subsidence of osseous calcium and preventing its loss. The function of calcitonin is to land hematic calcium onto the bones and convert it into osseous calcium, by which bones will be strengthened. Calcitonin has been used for treating Paget's disease (osteitis deformans), hypercalcemia caused by neoplastic diseases, vitamin D intoxication, and hyperparathyroidism by subcutaneous or intramuscular administration. The absorption of calcitonin by the nasal route remains poor and highly variable [71]. Therefore, preparing a potent oral formulation with this peptide would provide a valuable alternative [72].

Calcitonin has been encapsulated into polyacrylamide nanospheres [73], PIBCA nanocapsules [73], and chitosan nanoparticles[74]. Salmon calcitonin was also encapsulated into polystyrene nanoparticles composed of graft copolymers with a hydrophobic backbone and hydrophilic branches, prepared by the dispersion copolymerization of hydrophilic polyvinyl macromonomers with styrene in a polar solvent [75]. When administered orally to rats, the decrease in blood concentration of ionized calcium was considerably greater than after oral administration of calcitonin in water. The absorption enhancement of calcitonin by these nanoparticles probably results from both bioadhesion to the GI mucosa and the increase of the stability of calcitonin in the GIT.

\section{Cyclosporine A}

Cyclosporine is a cyclic nonribosomal peptide produced by the fungus Hypocladium inflatum gams, initially isolated from a Norwegian soil sample. Apart from its use in transplant medicine because of its immunosuppressive properties, cyclosporine is also used in treatment of psoriasis and infrequently of rheumatoid arthritis and related diseases, although it is used only in severe cases. More recently, cyclosporine has begun to be used as an aid in treating patients suffering from ulcerative colitis with positive results. After oral administration this compound is absorbed only incompletely and variably, leading to a relative bioavailability of less than $50 \%$ [72]. In contrast to most peptides, it is particularly lipophilic. It is practically insoluble in water and is soluble in alcohol. These characteristics are favorable for encapsulation in particles. Several polymers have been used including poly(isohexylcyanoacrylate) (PIHCA) and poly( $\varepsilon$-caprolactone) (PCL) [76]. Cyclosporine was encapsulated in PIHCA by interfacial and emulsion polymerization [72]. The nanoparticle formulation had a notably increased bioavailability compared with that of the commercial formulation.

\section{Anticancer drugs}

Significant advances have already taken place in the treatment of some malignancies; however, there has been little progress in the treatment of most common solid tumors such as those of the breast, lung, colorectum, and brain. To 
be effective the drug must reach a given concentration close to the tumor cells, which is far from being the case everywhere within the tumor. The special structure and location of solid tumors such as the blood-brain barrier is also considered an obstacle for many drugs, such as antibiotics, antineoplastic agents, and a variety of drugs active in the central nervous system, especially neuropeptides [29]. In addition to such a constitutive resistance to treatments as a result of physiologic considerations, the emergence of multidrug resistance is often an additional problem to be solved, including overexpression of the transmembrane glycoprotein Pgp (efflux with PgP pump), multidrug resistance protein, and glutathione $S$-transferase or topoisomerase modifications [77]. Because of this situation higher doses of anticancer drugs must be given. However, toxicity places limitations on therapy with most chemotherapeutic agents, including cardiotoxicity and myelosuppression [78].

Consequently, there is a need for a new method of administration that could concentrate the drug close to the tumor site, avoiding widespread distribution. Because drug targeting can modulate drug distribution, the use of nanoparticle carriers has been proposed to have potential for increasing the efficacy of chemotherapy while reducing adverse effects. Nanoparticles show a tendency for accumulation in certain tumors [79-81] for several possible reasons: various tumors show enhanced endocytotic activity; nanoparticles may easily escape through leaky endothelial tissue in the tumor; and finally, nanoparticles may be adsorbed on the surface of blood vessels in the tumor due to an enhanced bioadhesiveness for these particles of blood vessel walls in the tumor. Curiously, some studies have demonstrated that nanoparticles can overcome the blood-brain barrier to deliver drugs to the brain $[82,83]$. An example of this ability to overcome the blood-brain barrier is dalargin, a peptide that shows good stability in the bloodstream. Normally the topical injection of this peptide induces analgesia, whereas the systemic administration of this peptide shows no effect on central analgesic mechanisms [84]. This peptide was nanoencapsulated in poly(butylcyanoacrylate) with polysorbate 85 coating (Science Lab, Texas). The antinociceptive effect obtained with dalargin by this delivery route was not as pronounced though rather prolonged [82]. In the literature concerning tumor therapy, two major types of particle carriers are most frequently encountered: PACA and poly(lactic acid) nanoparticles.

\section{Vaccines}

The GIT is constantly invaded by potentially harmful antigens, which are usually destroyed by the mucosal barrier via a combination of nonimmunologic barriers such as gastric acidity, proteolytic enzymes, peristalsis, commensal microflora, and mucus, as well as the immunologic barrier $[85,86]$. The immune response is stimulated when antigens gain access to lymphoid tissue within the GIT. The gutassociated lymphoid tissue is distributed into four anatomic regions [87]: the lamina propria, which contains large numbers of plasma cells as well as macrophages, neutrophils, eosinophilis, and mast cells; the intraepithelial lymphocytes, which are dispersed between the epithelial cells of the mucosal membrane; isolated lymphoid follicles, present throughout the intestine and colon; PP, which are clusters of lymphoid follicles along the wall of the small intestine [88]. Lymphoid tissue of the lamina propria and intraepithelial lymphocytes are collectively known as the diffuse lymphoid tissue. An immune response is elicited through lymphoid tissue of the PP and isolated lymphoid follicles [88].

Thus far oral immunization has been accomplished by either the use of live attenuated organisms or the use of peptides, which have the capacity to bind and be absorbed at the intestinal level and to generate both a local mucosal response and, if necessary, a systemic immune response [88]. A third method of oral immunization based on DNA vaccines that has recently been developed is gaining ever more attention. DNA vaccines elicit immune responses by expressing proteins in vaccinated hosts. The DNA vaccines are simple rings of DNA containing a gene encoding an antigen, and a promoter/terminator to cause expression of the gene in mammalian cells [89]. This may constitute a future approach for the administration of antigenic peptides.

Oral vaccination may fail for several reasons, including: failure to swallow the vaccine, inactivation by gastric acid and intestinal enzymes, poor bioavailability, interference from other bacteria and viruses in the GIT, mutual interference if more than one type of live vaccine is administered concurrently, and excessively rapid transit of the vaccine through the intestine limiting its binding to mucosal cell receptors and hence stimulation of an adequate immune response. To overcome the need for higher and more frequent dosing required by oral administration and to minimize vaccine failure, researchers have attempted several strategies including particulate drug delivery systems and subsequent delivery mainly through the M cells of the PP.

The use of particulate carrier systems for oral delivery of antigens might be expected to confer several advantages over alternative approaches, including: promotion by particles of uptake by the PP; protection against antigen degradation; the possibility of delivering several antigens simultaneously; the added ability to incorporate immunologic adjuvants; avoidance of immunity to the carrier, thus permitting frequent boosting; the capacity for controlled or "pulsed" release of antigen; the potential possibility of directing the carrier to the uptake site by adding a specific targeting moiety to promote the efficiency of delivery [87].

It was first suggested more than 30 years ago that the soluble or particulate nature of an antigen could affect the response to its oral administration [90]. Subsequently it was demonstrated that the association of a soluble antigen with a particulate carrier (polyacrylamide microparticles, 1-3 $\mu \mathrm{m}$ ) before oral administration led to the induction of an enhanced secretory immune response [91], which was 
considered to be due to the greater ability of particulates to gain access to the PP. However, the only immune response measured was that elicited by a hapten conjugated to a carrier protein, whereas responses to the carrier protein were not determined [91]. Later work [92] demonstrated that latex particles with a protein coating were taken up into the PP, again highlighting the potential of particulate carriers as antigen delivery systems for oral immunization [92].

The first applications of nanoparticles were as adjuvants for vaccines [93,94]. Viruses, virus subunits, bacterial toxoids, peptides, and other antigens have been incorporated in or adsorbed by nanoparticles [95,96]. Many polymers have been applied such as poly(methylmethacrylate) [94], poly(D,L-lactide-co-glycolide) [24], and polystyrene nanoparticles $[38,39,97]$, representing efficient and possibly safe carriers for vaccines. It was interesting to note that the amount of uptake by the PP was dependent on size. The critical size of the particles taken up by the PP in these studies varied, but this difference may be due to physicochemical differences in the administered particles, or to the experimental design or method of analysis of particulate uptake. However, all studies demonstrated numerous advantages to nanoparticles over larger particles.

Coupled with advances in molecular biology, virology, immunology, and controlled delivery, nanoparticulate systems may be the next generation of effective vaccines in the field of oral immunization [22].

\section{Parenteral administration}

Potential applications of colloidal drug carriers administered intravenously can be summarized in terms of the concentration of drugs in accessible sites, the rerouting of drugs away from sites of toxicity, and increasing the circulation half-life of labile or rapidly eliminated drugs such as peptides and proteins. Because colloidal drug carriers are naturally concentrated within macrophages, they are well suited as drug carriers to these particular cells. The use of peptides and polypeptides for human and animal treatment is problematic, because the tendency of some of these drugs to be rapidly degraded by proteolytic enzymes in the GIT and not to be absorbed through the intestinal wall means they are generally ineffective by the oral route; thus they have generally been administered by parenteral routes.

\section{Anticancer drugs}

As described above, drug targeting can modulate drug distribution, and colloidal carriers have shown promise for increasing the efficacy of chemotherapy while reducing adverse effects. One of the most promising applications of nanoparticles is their use as carriers for anticancer agents.

Immunotherapy with macrophage activators has been suggested as an alternative to conventional therapy for treating metastatic tumors. Among these, muramyldipeptide (MDP) has promising properties in vitro but because of its hydrophilicity is cleared too rapidly to produce an antimetastatic effect in vivo [19]. MDP is a low-molecular- weight, soluble synthetic compound derived from the peptidoglycan of mycobacteria and is used as a macrophage activator that interacts with intracellular receptors. MDP penetrates poorly into macrophages and is eliminated rapidly after intravenous administration. These problems can be overcome by encapsulation within nanoparticles $[98,99]$. A lipophilic derivative of this substance, the muramyltripeptide-cholesterol (MTP-chol), was prepared [98] and successfully encapsulated in isobutylcyanoacrylate nanocapsules by an interfacial polymerization. The encapsulation of the MTP-chol into nanoparticles leads to a stimulation of the antimicrobial and anticancer activity of macrophages. As well, an antiangiogenesis peptide, arginine-rich hexapeptide, was encapsulated into chitosandextran sulfate nanoparticles [100] to achieve sustained release with the intention of prolonging biologic activity of the peptide. It was suggested that this peptide may be effective for the treatment of various human tumors and other angiogenesis-dependent diseases that are related to the action of vascular endothelial growth factor. These hydrophilic nanoparticles were prepared by a coacervation process under extremely mild conditions with ionic crosslinkage, without involving high temperatures or sonication, and may have potential as a carrier for small peptides.

\section{Hormones}

Human growth hormone-releasing factor (hGRF) is a hormone released from the arcuate nucleus of the hypothalamus that stimulates the release of growth hormone. The effects of growth hormone on the tissues of the body can generally be described as anabolic (building up). hGRF is used in the treatment of several diseases such as Turner's syndrome and Prader-Willi syndrome. However, frequent injections are required to produce an effective therapy. An alternative for reducing the drawbacks of parenteral administration of this peptide is to develop long-acting parenteral preparations. This approach, however, is complicated by the physicochemical characteristics of peptide [101]. Gautier et al. developed a nanoparticulate system with hGRF. In fact, PIHCA nanoparticles [101] were able to protect against enzymatic degradation and to deliver hGRF after subcutaneous administration.

\section{Other drugs}

Nanoparticles have been proposed as an intramuscular formulation for sustained release of testosterone [102] and for subcutaneous treatment of diabetes mellitus with insulinPIBCA nanospheres [36] and nanocapsules [51].

\section{Ophthalmic application}

Nanoparticles have shown promising results over the last 10 years in ophthalmology, providing protection of drug from chemical and enzymatic degradation, improved tolerance, increased corneal uptake, and longer intraocular half-life [103].

The first report on particulate systems for ocular delivery was in 1980 by Gurny and Taylor [104]. Subsequently, 
Table 1

Some biomedical applications of polymeric nanoparticles adapted from Murillo [126].

\begin{tabular}{ll}
\hline Biomedical applications & Drugs \\
\hline Chemotherapy & Calcitonin [73] \\
& Dalargin [82-84] \\
& MTP-chol [98] \\
& Progesterone [110] \\
& Cyclosporine [127] \\
& Doxorubicin [127] \\
& Endothelial vascular growth factor [128] \\
& Glycoproteins [129] \\
& HER 2-expressing murine sarcomas [130] \\
& HIV-1MN gp 120 [96] \\
Immunoprophylaxis & Cyclosporine [72,76] \\
& Insulin [67] \\
Antiinflammatory & Calcitonin [75] \\
Bioadhesion & Poorly water-soluble drugs [131] \\
& Contrast agents and other molecules \\
Diagnostic & {$[132-134]$} \\
& DNA [135] \\
Gene therapy &
\end{tabular}

various types of nanoparticles were proposed to take advantage of prolonged residence time, because the short elimination half-life of ophthalmologic drugs remains a major problem in ocular therapy [20]. Cyclosporine A was also nanoencapsulated in three important studies involving PCL [105], PACA [106,107], and chitosan [108] to evaluate aqueous suspensions of cyclosporine A-loaded nanoparticles [103]. The nanoparticle approach is not yet completely satisfactory, because the precorneal clearance is still too rapid. Of the three cyclosporine A carriers the most promising is chitosan because of the therapeutic levels achieved in periocular tissues and its good tolerance [103]; consequently it has been widely used in ocular drug formulations [109].

Pharmacologic efficiency may be influenced not only by the nature of the carrier but also by the physicochemical presentation of the drug. Progesterone was also associated with nanoparticles but in this case was less efficient than the administration of a simple aqueous solution [110]. This result was attributed to a high affinity of progesterone for the nanoparticles, which made the drug less available for corneal absorption. Nevertheless, it was found that the concentration of ${ }^{14} \mathrm{C}$-labeled PACA nanoparticles in the cornea, conjunctiva, nictitating membrane, and aqueous humor was three to five times higher in eyes in which a chronic inflammation had been induced [111]. This observation suggests that these nanoparticles have enhanced bioadhesiveness on inflamed tissues. It was demonstrated that nanoparticles adhere to inflamed ocular tissue at a level that is four times higher than in healthy tissue. These particles also hold promise for the targeting of antiinflammatory drugs to inflamed eyes [112].

\section{Pulmonary administration}

In contrast to intravenous or oral application, pulmonary application via inhalation is accompanied by several unique challenges [113], the first of which is the atomization of the drug formulation in a form suitable for inhalation. It is generally accepted that aerosol particles of 1 to $5 \mu \mathrm{m}$ are required for deposition in the alveolar region of the lung, which can be classified as the region of the highest systemic absorption. The primary influences on aerosol particle size and, ultimately, the site of aerosol deposition, include the design of the inhalation device as well as the physicochemical properties of the drug formulation [114].

Among the various drug delivery systems considered for pulmonary application, biodegradable polymeric nanoparticles demonstrate potential advantages to administration of peptidic and protein drugs such as insulin [115]. In comparison to liposomal formulations, polymeric nanoparticles may show a greater stability to the extreme forces generated during the nebulization process, thus eliminating the possibility of drug leakage [116,117]. An additional advantage of nanoparticle formulations is that particles with a diameter less than $1 \mu \mathrm{m}$ are more easily incorporated in the "respirable percentage" of aerosolized droplets [114]. In addition to the size of the individual particles, concentrations as well as surface characteristics play an important role in determining the physicochemical properties of the suspension, and subsequently, its behavior during nebulization [114]. Thus pulmonary application via inhalation presents unique challenges but also promising perspectives in nanoparticulate drug delivery systems.

\section{Other routes}

Colloidal drug carrier systems have been used to concentrate $\gamma$-interferon in the skin for the treatment of cutaneous herpes. Cytokine accumulates in the stratum corneum, rather than remaining on the surface as occurs after administration of a simple solution [118]. Other drugs such as minoxidil have been successfully encapsulated and administered by the transdermal route [119]. With regard to the nasal route, the nasal mucosa's high permeability affords easy access of drug to the absorption site. Nanoparticles loaded with drugs such as insulin [120,121], DNA [122], and tetanus toxoid [123] have been encapsulated and administered by this route.

These results are important, and the research on nanotechnology is consequently gaining momentum. An example of the success of nanotechnology is the recent entry of cyanoacrylate nanoparticles into Phase II clinical trials for use in the treatment of resistant cancers. Nevertheless, several issues remain to be resolved.

Finally, examples of biomedical applications of nanoparticles and various examples of drugs are summarized in Table 1.

\section{Conclusions}

Nanoparticles are particularly useful for formulating new drugs because they can provide protection from degradation in biologic fluids and promote penetration into cells. As 
shown in this review, there is a great deal of interest in the properties of nanoparticles and their potential applications. Nanoparticles, because of their sustained-release properties, subcellular size, and biocompatibility with tissue and cells, seem to hold promise for the achievement of these important objectives [124]. Nanoparticles permit alterations in the bioavailability of drugs and improve the pharmacokinetic profile of numerous drugs with biomedical purposes.

Finally, if nanoparticulate systems show great promise as a tool for the development of peptide and protein administration, their final success will depend heavily on the will of the pharmaceutical industry to develop new polymers, test their potential in therapeutics, and demonstrate their safety. Nanoparticulate systems able to improve the efficacy of both established drugs and new molecules will likely be available in the near future.

\section{References}

[1] Li Y-P, Pei Y-Y, Zhang X-Y, Gu Z-H, Zhou Z-H, Yuan W-F, et al. PEGylated PLGA nanoparticles as protein carriers: synthesis, preparation and biodistribution in rats. J Contr Rel 2001;71:203-11.

[2] McClean S, Prosser E, Meehan E, O’Malley D, Clarke N, Ramtoola $\mathrm{Z}$, et al. Binding and uptake of biodegradable poly-d,l-lactide microand nanoparticles in intestinal epithelia. Eur J Pharm Sci 1998; 6:153-63.

[3] Soppimath KS, Aminabhavi TM, Kulkarni AR, Rudzinski WE. Biodegradable polymeric nanoparticles as drug delivery devices. J Contr Rel 2001;70:1-20.

[4] Nobs L, Buchegger F, Gurny R, Allémann E. Current methods for attaching targeting ligands to liposomes and nanoparticles. J Pharm Sci 2004;93:1980-92.

[5] TenHoor C, Dressman J. Oral absorption of peptides and proteins. S.T.P. Pharma Sci 1992;2:301-12.

[6] Langguth P, Bohner V, Heizmann J, Merkle HP, Wolffram S, Amidon GL, et al. The challenge of proteolytic enzymes in intestinal peptide delivery. J Contr Rel 1997;46:39-57.

[7] Adibi SA, Kim YS. Peptide absorption and hydrolysis. In: Johnson LR, editor. Physiology of the gastrointestinal tract. New York: Raven Press; 1981. p. $1073-95$.

[8] Bohley P, Seglen PO. Proteases and proteolysis in the lysosome. Experientia 1992;151-7.

[9] Drasar BS, Hill MJ. Bacterial glycosidase. In: Drasar BS, Hill MJ, editors. Human intestinal flora. London, UK: Academic Press; 1974. p. $54-71$.

[10] Fix JA. Oral Contrled release technology for peptides: status and future prospects. Pharm Res 1996;13:1760 - 4 .

[11] Zhou XH. Overcoming enzymatic and absorption barriers to nonparenterally administered protein and peptide drugs. J Contr Rel 1994;29:239-52.

[12] Hochman J, Artursson P. Mechanisms of absorption enhancement and tight junction regulation. J Contr Rel 1994;29:253 - 67.

[13] Couvreur P, Puisieux F. Nano- and microparticles for the delivery of polypeptides and proteins. Adv Drug Del Rev 1993;10:141-62.

[14] Lee VHL, Dodda-kashi S, Grass OM, Rubas W. Oral route of peptide and protein drug delivery. In: Lee VHL, editor. Protein and peptide drug delivery. New York: Marcel Dekker; 1991. p. 691 - 738.

[15] Fukunaga M, Miller MM, Deftos LJ. Liposome-entrapped calcitonin and parathyroid hormone are orally effective in rats. Horm Metab Res 1991;23:166-7.

[16] Silva Cunha A, Grossiord JL, Puisieux F, Seiller M. Insulin in w/o/w multiple emulsions: preparation, characterization and determination of stability towards proteases in vitro. J Microencapsulation 1997; 14:311-9.

[17] Matsuzawa A, Morishita M, Takayama K, Nagai T. Absorption of insulin using water-in-oil-in-water emulsion from enteral loop in rats. Biol Pharm Bull 1995;18:1718-23.

[18] Morishita I, Morishita M, Takayama K, Machida Y, Nagai T. Hypoglycemic effect of novel oral microspheres of insulin with protease inhibitor in normal and diabetic rats. Int $\mathrm{J}$ Pharm 1992;78:9-16.

[19] Allémann E, Leroux JC, Gurny R. Polymeric nano-microparticles for the oral delivery of peptides and peptidomimetics. Adv Drug Del Rev 1998;34:171-89.

[20] Couvreur P, Dubernet C, Puisieux F. Controlled drug delivery with nanoparticles: current possibilities and future trends. Eur J Pharm Biopharm 1995;41:2-13.

[21] Panyam J, Labhasetwar V. Biodegradable nanoparticles for drug and gene delivery to cells and tissue. Adv Drug Del Rev 2003;55:329-47.

[22] Jaehere FD, Doelker E, Gurny R. Nanoparticles. In: Mathiowitz E, editor. Nanoparticles. New York: Wiley and Son, Inc; 1999. p. $641-64$.

[23] Jani P, Halbert GW, Langridge J, Florence AT. Nanoparticle uptake by rat gastrointestinal mucosa: quantitation and particles size dependency. J Pharm Pharmacol 1990;42:821-6.

[24] Eldridge JH, Hammond CJ, Meulbroek JA, Staas JK, Gilley RM, Tice TR. Controlled vaccine release in gut-associated lymphoid tissues. I. Orally administered biodegradable microspheres target the Peyer's patches. J Contr Rel 1990;11:205-14.

[25] Michel C, Aprahamian M, Defontaine L, Couvreur P, Damgé C. The effect of site of administration in the gastrointestinal tract on the absorption of insulin from nanocapsules in diabetic rats. J Pharm Pharmacol 1991;43:1-5.

[26] Damgé C, Aprahamian M, Humbert W, Pinget M. Ileal uptake of polyalkylcyanoacrylate nanocapsules in the rat. J Pharm Pharmacol 2000;52:1049-56.

[27] Kreuter J, Muller U, Munz K. Quantitative and microautoradiographic study on mouse intestinal distribution of polycyanoacrylate nanoparticles. Int J Pharm 1989;55:39-45.

[28] Aprahamian M, Michel C, Humbert W, Devissaguet J-P, Damgé C. Transmucosal passage of polyalkylcyanoacrylate nanocapsules as a new drug carrier in the small intestine. Biol Cell 1987;61:69-76.

[29] Vauthier C, Dubernet C, Fattal E, Pinto-Alphandary H, Couvreur P. Poly(alkylcyanoacrylates) as biodegradable materials for biomedical applications. Adv Drug Del Rev 2003;55:519-48.

[30] Florence AT. The oral absorption of micro and nanoparticulates: neither exceptional nor unusual. Pharm Res 1997;14:259-66.

[31] Hussain N. Recent advances in the understanding of uptake of microparticulates across the gastrointestinal lymphatics. Adv Drug Del Rev 2001;50:107-42.

[32] Jung T, Kamm W, Breitenbach A, Kaiserling E, Xiao JX, Kissel T. Biodegradable nanoparticles for oral delivery of peptides: is there a role for polymers to affect mucosal uptake? Eur J Pharm Biopharm 2000;50:147-60.

[33] Couvreur P. Polyalkylcyanoacrylates as colloidal drug carriers. Crit Rev Ther Drug Carrier Syst 1988;5:1-20.

[34] Allémann E, Gurny R, Doekler E. Drug-loaded nanoparticlespreparation methods and drug targeting issues. Eur $\mathrm{J}$ Pharm Biopharm 1993;39:173-91.

[35] Elamanchili P, Diwan M, Cao M, Samuel J. Characterization of poly (lactic-co-glycolic acid) based nanoparticulate system for enhanced delivery of antigens to dendritic cells. Vaccine 2004;22:2406-12.

[36] Couvreur P, Lenaerts V, Kante B, Roland M, Speiser PP. Oral and parenteral administration of insulin associated to hydrolyzable nanoparticles. Acta Pharm Technol 1980;26:220-2.

[37] Florence AT, Hillery AM, Hussain N, Jani PU. Nanoparticles as carriers for oral peptide absorption: studies on particle uptake and fate. J Contr Rel 1995;36:39-46. 
[38] Jani P, Florence AT, McCarthy DE. Further histological evidence of the gastrointestinal absorption of polystyrene nanospheres in the rat. Int J Pharm 1992;84:245-52.

[39] Jani P, McCarthy DE, Florence AT. Nanosphere and microsphere uptake via Peyer's patches: observation on the rate of uptake in the rat after a single oral dose. Int J Pharm 1992;86:239-46.

[40] Allémann E, Gurny R, Doelker E. Preparation of aqueous polymeric nanodispersions by a reversible salting-out process: influence of process parameters on particle size. Int J Pharm 1992;87:247-53.

[41] Hubert B, Atkinson J, Guerret M, Hoffman M, Devissaguet J-P, Maincent $P$. The preparation and acute antihypertensive effects of a nanocapsular form of darodipine, a dihydropyridine calcium entry blocker. Pharm Res 1991;8:734-8.

[42] Espuelas MS, Legrand P, Irache JM, Gamazo C, Orecchioni A-M, Devissaguet J-P, et al. Poly( $\varepsilon$-caprolactone) nanospheres as an alternative way to reduce amphotericin $\mathrm{B}$ toxicity. Int $\mathrm{J}$ Pharm 1997;158:19-27.

[43] Fessi H, Puisieux F, Devissaguet J-P, Ammoury N, Benita S. Nanocapsule formation by interfacial deposition following solvent displacement. Int J Pharm 1989;55:R1-R4.

[44] Ammoury N, Fessi H, Devissaguet J-P, Dubrasquet M, Benita S. Jejunal absorption, pharmacological activity, and pharmacokinetic evaluation of indomethacin-loaded poly(D,L-lactide) and poly(isobutyl-cyanoacrylate) nanocapsules in rats. Pharm Res 1991;8: $101-5$.

[45] Grangier JL, Puygrenier M, Gauthier JC, Couvreur P. Nanoparticles as carriers for growth hormone releasing factors (GRF). J Contr Rel 1991;15:3-13.

[46] Roques M, Damgé C, Michel C, Staedel C, Crémel G, Hubert P. Encapsulation of insulin for oral administration preserves interaction of the hormone with its receptor in vitro. Diabetes 1992;41:451-6.

[47] Hirai S, Ikenaga T, Matsuzawa T. Nasal absorption of insulin in dogs. Diabetes 1978;27:296-9.

[48] Saffran M, Kumar GS, Savariar C, Burnham JC, Williams F, Neckers DC. A new approach to the oral administration of insulin and other peptide drugs. Science 1986;233:1081-4.

[49] Cho YW, Flynn M. Oral delivery of insulin. Lancet 1989;2:1518-9.

[50] Patel HM, Ryman BE. Oral administration of insulin by encapsulation within liposomes. FEBS Lett 1976;62:60-3.

[51] Damgé C, Michel C, Aprahamian M, Couvreur P. New approach for oral administration of insulin with polyalkylcyanoacrylate nanocapsules as drug carrier. Diabetes 1988;37:246-51.

[52] Aboubakar M, Puisieux F, Couvreur P, Deyme M, Vauthier C. Study of the mechanism of insulin encapsulation in poly(isobutylcyanoacrylate) nanocapsules obtained by interfacial polymerization. J Biomed Mater Res 1999;47:568-76.

[53] Aboubakar M, Couvreur P, Pinto-Alphandary H, Gouritin B, Lacour B, Farinotti R, et al. Insulin-loaded nanocapsules for oral administration: in vitro and in vivo investigation. Drug Dev Res 2000;49:109- 17 .

[54] Oppenheim RC, Stewart NF, Gordon L, Patel HM. Production and evaluation of orally administered insulin nanoparticles. Drug Dev Ind Pharm 1982;8:531-46.

[55] Watnasirichaikul S, Davies NM, Rades T, Tucker IG. Preparation of biodegradable insulin nanocapsules from biocompatible microemulsions. Pharm Res 2000;17:684-9.

[56] Al Khouri N, Roblot-Treupel L, Fessi H, Devissaguet J-P, Puisieux F. Development of a new process for the manufacture of polyisobutylcyanoacrylate nanocapsules. Int J Pharm 1986;28:125-32.

[57] Damgé C, Michel C, Aprahamian M, Couvreur P, Devissaguet J-P. Nanocapsules as carriers for oral peptide delivery. J Contr Rel 1990;13:233-9.

[58] Pinto-Alphandary H. Visualization of insulin-loaded nanocapsules: in vitro and in vivo studies after oral administration to rats. Pharm Res 2003;207:1071-84.

[59] Michel C, Defontaine L, Aprahamian M, Couvreur P, Damgé C. Insulin nanocapsules: variations in the biological response depending on the administration site along the digestive tract. In: Whateley TL, editor. Microencapsulation of drugs. Chur, Switzerland: Hardwood Academic Publishers; 1992. p. 233-42.

[60] Damgé C, Vonderscher J, Marbach P, Pinget M. Poly(alkylcyanoacrylate) nanocapsules as a delivery system in the rat for octreotide, a long-acting somatostatin analogue. J Pharm Pharmacol 1997; 49:949-54.

[61] Michel C, Roques M, Couvreur P, Vranchx H, Baldschmidt P. Isobutylcyanoacrylate nanoparticles as drug carrier for oral administration of insulin. Proc Int Symp Contr Rel Bioact Mater 1991;18:97-8.

[62] Morishita M, Morishita I, Takayama K, Machida Y, Nagai T. Novel oral microspheres of insulin with protease inhibitor protecting from enzymatic degradation. Int J Pharm 1992;78:1-7.

[63] Mathiowitz E, Jacob JS, Jong YS, Carino GP, Chichering DE, Chaturverdi $\mathrm{P}$, et al. Biologically erodable microspheres as potential oral drug delivery systems. Nature 1997;386:410-4.

[64] Watnasirichaikul S, Rades T, Tucker IG. In vitro release and oral bioactivity of insulin in diabetic rats using nanocapsules dispersed in biocompatible microemulsion. J Pharm Pharmacol 2002;54:473 - 80.

[65] Elvassore N, Bertucco A, Caliceti P. Production of insulin-loaded poly(ethylene glycol)/poly(l-lactide) (PEG/PLA) nanoparticles by gas antisolvent techniques. J Pharm Sci 2001;90:1628-36.

[66] Gomez A, Bingham D, Juan L, Tang K. Production of protein nanoparticles by electrospray drying. J Aerosol Sci 1998;29:561 - 74 .

[67] Pan Y, Li Y, Zhao H, Zheng J, Xu H, Wei G, et al. Bioadhesive polysaccharide in protein delivery system: chitosan nanoparticles improve the intestinal absorption of insulin in vivo. Int J Pharm 2002;249:139-47.

[68] Sullivan CO, Birkinshaw C. In vitro degradation of insulin-loaded poly(n-butylcyanoacrylate) nanoparticles. Biomaterials 2004;25: 4375-82.

[69] Hillery AM, Toth I, Shaw AJ, Florence AT. Co-polymerized peptide particles (CPP) I: synthesis, characterization and in vitro studies on a novel oral nanoparticulate delivery system. J Contr Rel 1996; 41:271-81.

[70] Hillery AM, Toth I, Florence AT. Co-polymerized peptide particles II: oral uptake of a novel co-polymeric nanoparticulate delivery system for peptides. J Contr Rel 1996;42:65-73.

[71] Garcia-Fuentes M, Torres D, Alonso MJ. New surface-modified lipid nanoparticles as delivery vehicles for salmon calcitonin. Int J Pharm 2005;296:122-32.

[72] Allémann E, Leroux J-C, Gurny R. Polymeric nano- and microparticles for the oral delivery of peptides and peptidomimetics. Adv Drug Del Rev 1998;34:171-89.

[73] Lowe PJ, Temple CS. Calcitonin and insulin in isobutylcyanoacrylate nanocapsules: protection against proteases and effect on intestinal absorption in rats. J Pharm Pharmacol 1994;46:547-52.

[74] Kawashima Y, Yamamoto H, Takeuchi H, Kuno Y. Mucoadhesive D,L-lactide/glycolide copolymer nanospheres coated with chitosan to improve oral delivery of calcitonin. Pharm Dev Technol 2000; 5:77-85.

[75] Sakuma S, Suzuki N, Kikuchi H, Hiwatari K, Akashi M, et al. Oral peptide delivery using nanoparticles composed of novel graft copolymers having hydrophobic backbone and hydrophilic branches. Int J Pharm 1997;149:93 - 106.

[76] Molpeceres J, Guzman M, Aberturas MR, Chacon M, Berges L. Application of central composite designs to the preparation of polycaprolactone nanoparticles by solvent displacement. J Pharm Sci 1996;85:206-13.

[77] Murray JC, Carmichael J. Targeting solid tumours: challenges, disappointments, and opportunities. Adv Drug Del Rev 1995; 17:117-27

[78] Dubernet C, Fattal E, Couvreur P. Nanoparticulate controlled release system for cancer therapy. In: Wise DL, editor. Handbook of pharmaceutical controlled release technology. New York: Marcel Dekker; 2000. p. 287-300. 
[79] Gipps EM, Arshady R, Kreuter J, Groscurth P, Speiser PP. Distribution of polyhexylcyanoacrylate nanoparticles in nude mice bearing human osteosarcoma. J Pharm Sci 1986;75:256-8.

[80] Grislain L, Couvreur P, Lenaerts V, Roland M, DeprezDecampeneere D, Speiser PP. Pharmacokinetics and distribution of a biodegradable drug-carrier. Int J Pharm 1983;15:335-45.

[81] Groscurth P, Gipps E, Kreuter J. Distribution of polyhexylcyanoacrylate nanoparticles in nude mice bearing human osteosarcoma. In: Rygaard JR, Brünner N, Graem N, Spang-Thomsen M, editors. Immune-deficient animals in biomedical research. Basel: Karger; 1987. p. 401.

[82] Kreuter J. Nanoparticulate systems for brain delivery of drugs. Adv Drug Del Rev 2001;47:65-81.

[83] Das D, Lin S. Double-coated poly(butylcynanoacrylate) nanoparticulate delivery systems for brain targeting of dalargin via oral administration. J Pharm Sci 2005;94:1343-53.

[84] Schroeder U, Sommerfeld P, Sabel BA. Efficacy of oral dalarginloaded nanoparticle delivery across the blood-brain barrier. Peptides 1998; 19:777-80.

[85] Holmgren J, Lycke N. Immune mechanisms in enteric infections. In: Holmgren J, Linderberg A, Molby RE, editors. Development of vaccines and drugs against diarrhea. Bromley, UK: Studenlitteratur; 1986. p. 9-22.

[86] Walker RI, Owen RL. Intestinal barriers to bacteria and their toxins. Annu Rev Med 1988;41:393-400.

[87] O'Hagan DT, Palin KJ, Davis SS. Intestinal absorption of proteins and macromolecules and the immunological response. Crit Rev Ther Drug Carrier Syst 1987;4:197-220.

[88] Gilligan CA, Po LW. Oral vaccines: design and delivery. Int J Pharm 1991;75:1-24.

[89] Ma L. DNA vaccines: a review. J Intern Med 2003;253:402 - 10.

[90] Strannegard O, Yurchison A. Formation of agglutinating and reagenic antibodies in rabbits following oral administration of soluble and particulate antigens. Int Arch Allergy Appl Immunol 1969;35:579-90.

[91] Cox DS, Taubman MA. Oral induction of the secretory antibody response by soluble and particulate antigens. Int Arch Allergy Appl Immunol 1984;75:126-31.

[92] Jeurisson SHM, Kraal G, Sminia T. The role of Peyer's patches in intestinal humoral immune responses is limited to memory formation. Adv Exp Med Biol 1987;216A:257-65.

[93] Birrenbach G, Speiser PP. Polymerized micelles and their use as adjuvants in immunology. J Pharm Sci 1976;65:1763-6.

[94] Kreuter J, Mauler R, Gruschkau H, Speiser PP. The use of new polymethylmethacrylate adjuvants for split influenza vaccines. Exp Cell Biol 1976;44:12-9.

[95] Calvo P, Remuñán-Lopez C, Vila-Jato JL, Alonso MJ. Chitosan and chitosan/ethylene oxide-propylene oxide block copolymer nanoparticles as novel carriers for proteins and vaccines. Pharm Res 1997; $14: 1431-6$.

[96] Frey A, Neutra MR, Robey FA. Peptomer aluminum oxide nanoparticle conjugates as systemic and mucosal vaccine candidates: synthesis and characterization of a conjugate derived from the $\mathrm{C} 4$ domain of HIV-1MN gp 120. Bioconjug Chem 1997;8:424-33.

[97] Jani P, Florence AT, McCarthy D. Polystyrene nanosphere and microsphere uptake and translocation via the gut mucosa after a single oral dose. J Pharm Pharmacol 1991;43(Suppl):27p.

[98] Yu WP, Barrat G, Devissaguet J-P, Puisieux F. Anti-metastatic activity in vivo of MDP-L-alanyl-cholesterol (MTP-chol) entrapped in nanocapsules. Int J Immunopharmacol 1991;13:167-73.

[99] Seyler I, Appel M, Devissaguet J-P, Legrand P, Barratt G. Macrophage activation by a lipophilic derivative of muramyldipeptide within nanocapsules: investigation of the mechanism of drug delivery. J Nanoparticle Res 1999;1:91-7.

[100] Chen Y, Mohanraj VJ, Parkin JE. Chitosan-dextran sulfate nanoparticles for delivery of an anti-angiogenesis peptide. Lett Peptide Sci 2003;10:621-9.
[101] Gautier JC, Grangier JL, Barbier A, Dupont P, Pastor G, Couvreur P. Biodegradable nanoparticles for subcutaneous administration of growth hormone releasing factor (hGRF). J Contr Rel 1992;20: 67-78.

[102] Gurny R, Banker GS, Buri P. Développment d'un injectable de testostérone à action prolongée à base de latex biodégradable. Proc III Congr Hispano-français Biopharm Pharmacocin 1979;173-9.

[103] Lallemand F, Felt-Baeyens O, Besseghir K, Behar-Cohenc F, Gurny R. Cyclosporine A delivery to the eye: a pharmaceutical challenge. Eur J Pharm Biopharm 2003;56:307-18.

[104] Gurny R, Taylor D. Development and evaluation of a prolonged acting drug delivery system for the treatment of glaucoma. In: Rubinstein MHE, editor. Proceedings of the International Symposium of the British Pharmaceutical Technology Conference-Solid Dosage Research Unit. Liverpool; 1980.

[105] Calvo P, Sánchez A, Martinez J, López MI, Calonge M, Pastor JC, et al. Polyester nanocapsules as new topical ocular delivery systems for cyclosporin A. Pharm Res 1996;13:311-5.

[106] Zimmer A, Kreuter J, Robinson JR. Studies on the transport pathway of PBCA nanoparticles in ocular tissues. J Microencapsulation 1991;8:497-504.

[107] Le Bourlais CA, Chevanne F, Turlin B, Acar L, Zia H, Sado PA, et al. Effect of cyclosporine A formulations on bovine corneal absorption: ex-vivo study. J Microencapsulation 1997;14:457-67.

[108] Campos AMD, Sánchez A, Alonso MJ. Chitosan nanoparticles: a new vehicle for the improvement of the delivery of drugs to the ocular surface. Application to cyclosporin A. Int J Pharm 2001;224:159-68.

[109] Campos AMD, Diebold Y, Carvalho ELS, Sánchez A, Alonso MJ. Chitosan nanoparticles as new ocular drug delivery systems: in vitro stability, in vivo fate, and cellular toxicity. Pharm Res 2004; 21:803-10.

[110] Lee VHK, Wood RW, Kreuter J, Harmia T, Robinson JR. Ocular drug delivery of progesterone using nanoparticles. J Microencapsulation 1986;3:213-8.

[111] Diepold R, Kreuter J, Guggenbuhl P, Robinson JR. Distribution of poly-hexyl-2-cyano $\left[3-{ }^{14} \mathrm{C}\right]$ acrylate nanoparticles in healthy and chronically inflamed rabbit eyes. Int J Pharm 1989;54:149-53.

[112] Diepold R, Kreuter J, Himber J, Gurny R, Lee VH, Robinson JR, et al. Comparison of different models for the testing of pilocarpine eyedrops using conventional eyedrops and a novel depot formulation (nanoparticles). Graefes Arch Clin Exp Ophthalmol 1989;227: $188-93$.

[113] Dailey LA, Schmehl T, Gessler T, Wittmar M, Grimminger F, Seeger W, et al. Nebulization of biodegradable nanoparticles: impact of nebulizer technology and nanoparticle characteristics on aerosol features. J Contr Rel 2003;86:131 - 44 .

[114] McCallion ON, Taylor KM, Thomas M, Taylor AJ. Nebulization of fluids of different physicochemical properties with air-jet and ultrasonic nebulizers. Pharm Res 1995;12:1682-8.

[115] Mansouri S, Lavigne P, Corsi K, Benderdour M, Beaumont E, Fernandes JC. Chitosan-DNA nanoparticles as non-viral vectors in gene therapy: strategies to improve transfection efficacy. Eur J Pharm Biopharm 2004;57:1-8.

[116] Bridges PA, Taylor KM. Nebulizers for the generation of liposomal aerosols. Int J Pharm 1998;173:117-52.

[117] Leung KKM, Bridges PA, Taylor KMG. The stability of liposomes to ultrasonic nebulization. Int J Pharm 1996;145:95-102.

[118] Weiner N, Williams N, Birch G, Ramachandran C, Shipman CJ, Flynn G. Topical delivery of liposomally encapsulated interferon evaluated in a cutaneous herpes guinea-pig model. Antimicrob Agents Chemother 1989;33:1217-21.

[119] Shim J, Kang HS, Park W-S, Han S-H, Kim J, Chang I-S. Transdermal delivery of minoxidil with block copolymer nanoparticles. J Contr Rel 2004;97:477-84.

[120] Fernández-Urrusuno R, Calvo P, Remunán-López C, Vila-Jato JL, Alonso MJ. Enhancement of nasal absorption of insulin using chitosan nanoparticles. Pharm Res 1999;16:1576-81. 
[121] Dyer AM, Hinchcliffe M, Watts P, Castile J, Jabbal-Gill I, Nankervis R, et al. Nasal delivery of insulin using novel chitosan based formulations: a comparative study in two animal models between simple chitosan formulations and chitosan nanoparticles. Pharm Res 2002;19:998-1008.

[122] Cui Z, Mumper RJ. Intranasal administration of plasmid DNAcoated nanoparticles results in enhanced immune responses. J Pharm Pharmacol 2002;54:1195-203.

[123] Tobio M, Gref R, Sánchez A, Langer R, Alonso MJ. Stealth PLAPEG nanoparticles as protein carriers for nasal administration. Pharm Res 1998;15:270-5.

[124] Schaffazick SR, Guterres SS, Freitas LL, Pohlmann AR. Caracterização e estabilidade fîsico-quimica de sistemas polimericos nanoparticulados para administração de fármacos. Química Nova 2003; 26:726-37.

[125] Dorkoosh FA, Verhoef JC, Rafiee-Tehrani M, Borchard G, Junginger HE. Peroral drug delivery systems for peptides and proteins. S.T.P. Pharma Sci 2002;12:213-21.

[126] Murillo M, Espuelas S, Prior S, Vitas AI, Renedo MJ, Goni MM, et al. Controlled liberation of active principles by means of new galenic formulations. Rev Med Univ Navarra 2001;45:19-34.

[127] Soma CE, Dubernet C, Bentolila D, Benita S, Couvreur P. Reversion of multidrug resistance by co-encapsulation of doxorubicin and cyclosporin A in polyalkylcyanoacrylate nanoparticles. Biomaterials 2000;21:1-7.

[128] Monsky WL, Fukumura D, Gohongi T, Ancukiewcz M, Weich HA, Torchilin VP, et al. Augmentation of transvascular transport of macromolecules and nanoparticles in tumours using vascular endothelial growth factor. Cancer Res 1999;59:4129-35.

[129] Lemoine D, Préat V. Polymeric nanoparticles as delivery system for influenza virus glycoproteins. J Contr Rel 1998;54:15-27.

[130] Gu XG, Schmitt M, Hiasa A, Nagata Y, Ikeda H, Sasaki Y, et al. A novel hydrophobized polysaccharide/oncoprotein complex vaccine induces in vitro and in vivo cellular and humoral immune responses against HER2-expressing murine sarcomas. Cancer Res 1998;58: 3385-90.

[131] Ponchel G, Irache JM. Specific and non-specific bioadhesive particulate systems for oral delivery to the gastrointestinal tract. Adv Drug Del Rev 1998;34:191-219.

[132] Anderson SA, Rader RK, Westlin WF, Null C, Jackson D, Lanza $\mathrm{GM}$, et al. Magnetic resonance contrast enhancement of neovasculture with $\alpha(\mathrm{v})-\beta$-(3)-targeted nanoparticles. Magn Reson Med 2000;44:433-9.

[133] Schaertl S, Meyer-Almes FJ, López-Calle E, Siemers A, Kramer PA. A novel and robust homogeneous fluorescence-based assay using nanoparticles for pharmaceutical screening and diagnostics. J Biomol Screen 2000;5:227-38.

[134] Perrin A, Theretz A, Lanet V, Vialle S, Mandrand B. Immunomagnetic concentration of antigens and detection based on scanning force microscopic immunoassay. J Immunol Methods 1999;224:77-87.

[135] Truong-Le VL, Walsh SM, Schweibert E, Mao HQ, Guggino WB, August JT, et al. Gene transfer by DNA-gelatin nanospheres. Arch Biochem Biophys 1999;361:47-56. 